\title{
Imaging tests in determination of brain death
}

\author{
Aad van der Lugt
}

Received: 18 August 2010 / Accepted: 18 August 2010 /Published online: 5 September 2010

(C) The Author(s) 2010. This article is published with open access at Springerlink.com

In this issue, an excellent review is published on the imaging findings in non-neonatal hypoxic-ischemic encephalopathy [1]. The authors also go into detail on imaging "brain death", an entity that is currently causing debate as far as the imaging approach is concerned.

Brain death refers to the irreversible end of all brain activity due to necrosis of neurons. The diagnosis of brain death allows organ donation for transplantation or withdrawal of life support. Legal standard and/or practice guidelines are currently present in most countries.

There is uniform agreement on the clinical neurological examination to evaluate absence of brain function. This examination includes the assessment of coma, the absence of brain reflexes, and the assessment of apnea. Some guidelines require a confirmatory test for the diagnosis of brain death while in others it is optional to use these tests. However, there is considerable variation in the type of additional confirmatory tests [2].

Confirmatory tests can be classified into two categories: confirmation of loss of electrical activity (electroencephalography or somatosensory-evoked potentials) and demonstration of loss of cerebral blood flow (cerebral angiography, transcranial doppler ultrasonography, or cerebral scintigraphy).

Although the role of confirmatory tests, has been debated [3], they could be useful (1) to shorten the observation time; (2) when components of clinical testing cannot be reliably evaluated, e.g., when the apnea test have to be aborted due to progressive hypotension or hypoxemia;

\footnotetext{
A. van der Lugt $(\square)$

Department of Radiology, Erasmus MC,

University Medical Centre Rotterdam,

's-Gravendijkwal 230,

3015 CE Rotterdam, Netherlands

e-mail: a.vanderlugt@erasmusmc.nl
}

(3) in medical conditions that may confound the clinical testing, e.g., drug intoxication; (4) in young children in whom the assessment of brain death is complicated because the neurological examination is more difficult and the immature nervous system is more resilient to certain forms of injury, and (5) to increase diagnostic confidence.

Cerebral (digital subtraction) catheter angiography has been the reference standard for the assessment of cerebral blood flow $[4,5]$. However catheter angiography is an invasive, timeconsuming procedure, which needs an experienced neuroradiologist and the availability of an angiography suite. Therefore, new non-invasive radiological tests like MRI, MRA, and CT angiography (CTA) have been proposed to

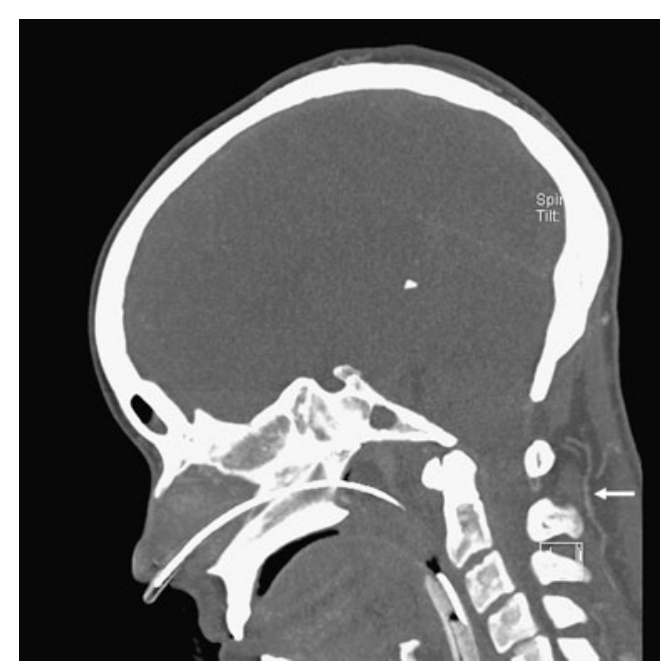

Fig. 1 Six-millimeter maximum intensity projection in sagital plane of CTA images obtained $60 \mathrm{sec}$ after contrast material injection. No enhancement of intracranial arteries is visible. Enhancement of a side branch of the external carotid artery (arrow) proves the correct injection and arrival of contrast material in the large neck arteries. Based on the criteria, brain death was confirmed 
Fig. 2 CTA images of a 7-yearold girl with brain death according to clinical criteria. Six-millimeter maximum intensity projection in coronal (a) and sagital (b) plane of CTA images obtained $60 \mathrm{sec}$ after contrast material injection. The pericallosal arteries and the basialar artery are opacified. The internal cerebral veins, the great cerebral vein, and the straight sinus are not opacified. Based on the criteria, brain death cannot be confirmed
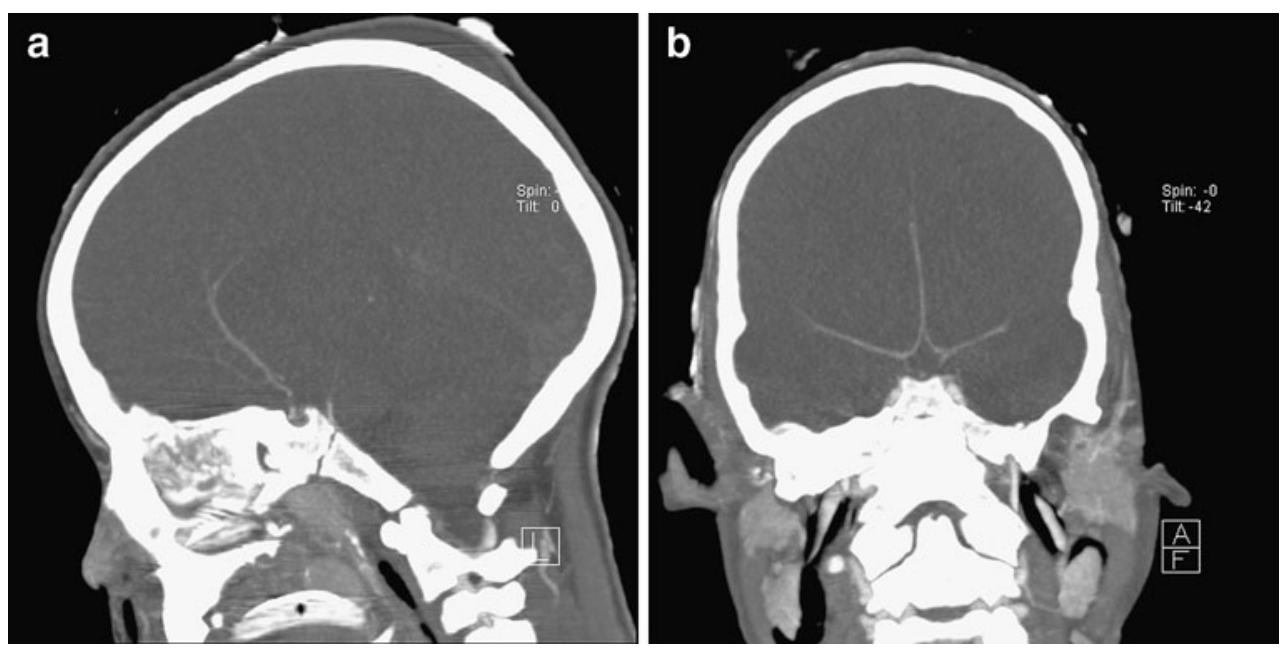

replace catheter angiography. Studies on MRI and MRA dated back to $2002[6,7]$, but CTA has recently attracted attention.

The accuracy of CTA for brain death diagnosis was first demonstrated in a study by Dupas et al. [8]. CTA demonstrated no opacification of the pericallosal arteries, cortical segments of the cerebral arteries, the internal cerebral veins, and the great cerebral vein in all 14 patients diagnosed with brain death (sensitivity 100\%), while all these vessels opacified in 11 normal controls (specificity $100 \%$ ) [8]. Based on this publication, France and the Netherlands accepted CTA as a confirmatory test for brain death diagnosis. However, the high sensitivity was not repeated in newer studies, which reported that intracranial opacification on CTA was present in a substantial number of patients (11-48\%) meeting existing criteria for brain death [9-13]. It is important to realize that the accuracy of CTA in the diagnosis of brain death is dependent on the applied criteria. Adapting the criteria proposed by Dupas et al. to opacification of the cortical segments of the middle cerebral arteries and the internal cerebral veins only leads to an increase of the sensitivity from $63 \%$ to $86 \%$ [12]. Absence of enhancement of the internal cerebral veins is probable the most relevant angiographic criterium for brain death $[9,12]$

Simple copying of the brain death criteria used for catheter angiography to CTA is not the way to go. Opacification of intracranial arteries does not necessarily mean the presence of cerebral blood flow. It might well be that it is caused by stasis of contrast material. This phenomenon has already been described in previous imaging studies in patients with brain death. Secondly, CTA is normally performed after $60 \mathrm{sec}$ of the contrast material injection and this delay may promote the dilution of contrast material into more distally located arteries. Finally, CTA has a higher sensitivity than catheter angiography for the detection of vascular contrast enhancement (Figs. 1 and 2).

Future research should define which CTA-derived parameters are relevant for the determination of brain death. Such studies should be performed in patients who meet the clinical and EEG criteria for brain death. Since most CTA studies on brain death have not evaluated the specifity of CTA, such studies should include also nonbrain-dead patients to assess the false-positive rate of CTA.

Newer techniques like CT perfusion (CTP) or 4D-CTA may increase the accuracy of CT-based techniques. CTP will allow the evaluation of brain tissue flow, while 4DCTA will visualize the arrival of contrast material in the major intracranial arteries and veins and will enhance the distinction between real flow and stasis of contrast material. More consensus within the neuroradiological community in Europe on the preferred imaging modality, the proper way to execute image acquisition and the relevant criteria for image interpretation is warranted.

Open Access This article is distributed under the terms of the Creative Commons Attribution Noncommercial License which permits any noncommercial use, distribution, and reproduction in any medium, provided the original author(s) and source are credited.

\section{References}

1. Gutierrez LG, Rovira A, Portela LAP, Leite CC, Lucato LT (2010) $\mathrm{CT}$ and MR in non-neonatal hypoxic-ischemic encephalopathy: radiological findings with pathophysiological correlations. Neuroradiology. doi:10.1007/s00234-010-0728-z

2. Wijdicks EF (2002) Brain death worldwide: accepted fact but no global consensus in diagnostic criteria. Neurology 58:20-25

3. Wijdicks EF (2010) The case against confirmatory tests for determing brain deaths in adults. Neurology 75:77-83 
4. Nau R, Prange HW, Klingelhöfer J, Kukowski B, Sander D, Tchorsch R, Rittmeyer K (1992) Results of four technical investigations in fifty clinically brain dead patients. Intensive Care Med 18:82-88

5. Bradac GB, Simon RS (1974) Angiography in brain death. Neuroradiology 7:25-28

6. Ishii K, Onuma $T$, Kinoshita $T$, Shiina $G$, Kameyama M, Shimosegawa Y (1996) Brain death: MR and MR angiography. AJNR Am J Neuroradiol 17:731-735

7. Karantanas AH, Hadjigeorgiou GM, Paterakis K, Sfiras D, Komnos A (2002) Contribution of MRI and MR angiography in early diagnosis of brain death. Eur Radiol 12:2710-2716

8. Dupas B, Gayet-Delacroix M, Villers D, Antonioli D, Veccherini MF, Soulillou JP (1998) Diagnosis of brain death using two-phase spiral CT. AJNR Am J Neuroradiol 19:641-647

9. Leclerc X, Taschner CA, Vidal A, Strecker G, Savage J, Gauvrit JY, Pruvo JP (2006) The role of spiral CT for the assessment of the intracranial circulation in suspected brain death. J Neuroradiol 33:90-95

10. Combes JC, Chomel A, Ricolfi F, d'Athis P, Freysz M (2007) Reliability of computed tomographic angiography in the diagnosis of brain death. Transplant Proc 39:16-20

11. Quesnel C, Fulgencio JP, Adrie C, Marro B, Payen L, Lembert N, El Metaoua S, Bonnet F (2007) Limitations of computed tomographic angiography in the diagnosis of brain death. Intensive Care Med 33:2229-2135

12. Frampas E, Videcoq M, de Kerviler E, Ricolfi F, Kuoch V, Mourey F, Tenaillon A, Dupas B (2009) CT angiography for brain death diagnosis. AJNR Am J Neuroradiol 30:1566-1570

13. Escudero D, Otero J, Marqués L, Parra D, Gonzalo JA, Albaiceta GM, Cofiño L, Blanco A, Vega P, Murias E, Meilan A, Roger RL, Taboada F (2009) Diagnosing brain death by CT perfusion and multislice CT angiography. Neurocrit Care 11:261-271 